\title{
Erratum to: Shiitake Mushroom Dermatitis: A Review
}

Matthew Paul Stephany ${ }^{1} \cdot$ Stella Chung ${ }^{2} \cdot$ Marc Zachary Handler $^{2}$.
Nancy Stefanie Handler $^{1} \cdot$ Glenn A. Handler $^{2} \cdot$ Robert A. Schwartz $^{2}$

Published online: 1 October 2016

(c) Springer International Publishing Switzerland 2016

\section{Erratum to: Am J Clin Dermatol (2016) \\ 17(5):485-489 \\ DOI 10.1007/s40257-016-0212-6}

In the original publication, the name of the first author is spelled incorrectly. It should read as "Matthew Paul Stephany" and this has been corrected in this erratum.

The online version of the original article can be found under doi:10.1007/s40257-016-0212-6.

Marc Zachary Handler zac0@aol.com

1 University of Nebraska Medical Center, College of Medicine, Omaha, NE, USA

2 Dermatology Department, Rutgers, New Jersey Medical School, Newark, NJ, USA 